\title{
In vitro Impact of Limited Exposure to Subtherapeutic Concentrations of Chlorhexidine Gluconate on the Adhesion-Associated Attributes of Oral Candida Species
}

\author{
Arjuna N.B. Ellepola ${ }^{a}$ Rachel Chandy ${ }^{b}$ Zia U. Khan ${ }^{b}$ \\ ${ }^{a}$ Department of Bioclinical Sciences, Faculty of Dentistry, and ${ }^{b}$ Department of Microbiology, Faculty of Medicine, \\ Kuwait University, Safat, Kuwait
}

\section{Key Words}

Candida · Adhesion - Buccal epithelial cells · Denture acrylic .

Cell surface hydrophobicity. Chlorhexidine gluconate

\begin{abstract}
Objective: Candida albicans and its non-albicans counterparts, such as C. tropicalis, C. krusei, C. glabrata and C. dubliniensis, are the major etiological agents of oral candidosis. Their adherence to buccal epithelial cells (BEC), denture acrylic surfaces (DAS) and cell surface hydrophobicity (CSH) are attributes associated with yeast colonization and infection. Chlorhexidine gluconate (CG) is a widely used antiseptic in dentistry. When administered, the diluent effect of saliva and the cleansing effect of the oral musculature reduce its bioavailability, compromising its efficacy. Hence, intraorally, Candida undergoes a transient exposure to high CG concentrations, and thereafter it is likely to be subtherapeutic. Therefore, the impact of CG on adhesion to BEC, DAS and $\mathrm{CSH}$ of different oral Candida species was investigated following brief exposure to three subtherapeutic concentrations of CG. Materials and Methods: Ten oral isolates of each of the above five Candida species obtained in Kuwait from oral rinse samples were exposed to $0.00125,0.0025$ and $0.005 \%$ CG for $30 \mathrm{~min}$. Subsequently, the yeast adhesion to $\mathrm{BEC}, \mathrm{DAS}$ and $\mathrm{CSH}$ was determined. The data were analyzed
\end{abstract}

using ANOVA Dunnett's t tests. Results: Exposure to the lowest dilution $(0.00125 \%)$ of CG did not elicit a noteworthy collective suppression on all three adhesion traits evaluated. Exposure to $0.0025 \%$ CG curtailed the adhesion to BEC, DAS and CSH of Candida species by $50.89,40.79$ and $24.58 \%$, respectively $(p<0.001)$. Exposure to the highest concentration $(0.005 \%)$ of CG reduced the adhesion to BEC, DAS and CSH of Candida species by $64.68,54.59$ and $50 \%$, respectively $(p<0.001)$. Conclusions: Brief exposure to subtherapeutic concentrations of CG suppressed the adhesion to BEC, DAS and CSH of oral Candida species, indicating probable pharmacodynamics that may potentiate its antiseptic properties.

(c) 2016 S. Karger AG, Basel

\section{Introduction}

Oral yeast infections due to Candida albicans and nonalbicans Candida species are common in compromised patient population groups [1]. Such oral yeast infections and the level of salivary Candida closely correlate with the degree of host immunosuppression, and are predictive of the underlying disease progression, especially in HIV disease [1]. Globally, C. albicans is by far the most prevalent of all the Candida species [1]. However, infections due to non-albicans Candida species, such as $C$. tropicalis, $C$.

\begin{tabular}{ll}
\hline KARGER & $\begin{array}{l}\text { ( ) 2016 S. Karger AG, Basel } \\
1011-7571 / 16 / 0254-0355 \$ 39.50 / 0 \quad \text { Karger }\end{array}$ \\
$\begin{array}{l}\text { E-Mail karger@karger.com } \\
\text { www.karger.com/mpp }\end{array}$ & $\begin{array}{l}\text { Thisis an Open Access article licensed under the terms of the } \\
\text { Creative Commons Attribution-NonCommercial 3.0 Un- } \\
\text { ported license (CC BY-NC) (www.karger.com/OA-license), } \\
\text { applicable to the online version of the article only. Distribu- } \\
\text { tion permitted for non-commercial purposes only. }\end{array}$
\end{tabular}

Dr. Arjuna N.B. Ellepola, BDS, PhD Department of Bioclinical Sciences Faculty of Dentistry, Kuwait University PO Box 24923, Safat 13110 (Kuwait) E-Mail arjuna@hsc.edu.kw 
krusei, C. glabrata and C. dubliniensis, are becoming increasingly common [1]. These organisms are thought to be emerging as pathogens due to their varied virulent attributes. For instance, C. krusei is intrinsically azole resistant, whilst $C$. glabrata had been reported to acquire azole resistance, causing serious and persistent infections in immunocompromised patients [2,3]. Similarly, C. tropicalis is frequently acquired from oral niches of HIV-infected patients [1]. Furthermore, C. dubliniensis is now universally recognized as a close relative of $C$. albicans with almost similar virulent attributes $[1,3]$. Fluconazole resistance has been witnessed in this yeast acquired from $\mathrm{HIV}$-infected individuals, as well as resistance to the newer antifungals, voriconazole and itraconazole [4-6]. In general, resistance to nearly all antifungal agents has been reported in clinical Candida isolates, signifying the urgent necessity for a substitute or adjunct antifungals [7].

The adherence of Candida to human oral mucosal surfaces is an essential prerequisite for the colonization process and infection, and a direct correlation between the enhanced yeast adhesion to the mucosa and their infectivity has been demonstrated [8]. It is also believed that the ability of Candida species to adhere to denture acrylic surfaces (DAS) is important in the pathogenesis of Candida-induced denture stomatitis $[8,9]$. The relative cell surface hydrophobicity (CSH) of Candida, which modifies the initial encounter between the fungus and the host, is considered a significant nonbiological trait allied to candidal adherence to either biotic or abiotic surfaces, such as oral prostheses [10]. It has also been noted that hydrophobic Candida are more pathogenic than their relatively more hydrophilic counterparts [10]. Studies have also shown positive correlations between the relative $\mathrm{CSH}$ of Candida and its adhesion to oral buccal epithelial cells (BEC) as well as DAS $[11,12]$.

Chlorhexidine gluconate (CG) is prescribed as an antiseptic mouthwash in routine dentistry because of its wide antimicrobial spectrum, which also includes Candida species [13]. CG is used as an adjunct for traditional antimycotic agents in the management of oral yeast infections, including Candida-associated denture stomatitis [14]. The antimycotic activity of CG has been shown both in vivo and in vitro, although most of these tests were focused on C. albicans species [14]. For instance, the exposure of either C. albicans isolates or BEC to $0.2 \%$ CG has been shown to suppress candidal adherence to BEC from healthy individuals or diabetics [15]. Others have shown that with C. albicans and its close phenotypic relative $C$. dubliniensis, CG is effective in suppressing CSH and adhesion to DAS $[16,17]$. Therefore, by suppressing Can- dida adhesion to BEC, DAS and their $\mathrm{CSH}$, mouthwashes containing CG may reduce the pathogenic potential of the yeast.

Although the pharmacodynamics of oral rinse agents have not been studied extensively, it is known that after an oral rinse with CG this antiseptic will be almost totally removed from the oral cavity during the first hour due to the diluent effect of saliva and the cleansing effect of the oral musculature, thus compromising its therapeutic efficacy [18]. As a result, Candida is likely to be briefly exposed to high concentrations of CG immediately after administration, and eventually to residual low subtherapeutic concentrations. The impact of such low concentrations of CG on the adhesion of different oral Candida species obtained from a single geographic locale to BEC, DAS and $\mathrm{CSH}$ has not been reported previously. Hence, the main aim of the current investigation was to evaluate the adhesion to five different oral Candida species (C. albicans, C. tropicalis, C. krusei, C. glabrata and C. dubliniensis) obtained from Kuwait University Dental Clinic to BEC, DAS and the relative CSH following limited exposure to three different subtherapeutic concentrations of CG (i.e. $0.00125,0.0025$ and $0.005 \%$ ).

\section{Materials and Methods}

\section{Organisms}

Oral Candida isolates from patients attending the Kuwait University Dental Clinic that were obtained in a previous study were used here [19]. Ten isolates each of C. albicans and the non-albicans species of Candida studied - C. krusei, C. tropicalis, C. glabrata and C. dubliniensis - were used (i.e. a total of 50 Candida isolates). The identification of the isolates was reconfirmed by observing colony colors on CHROMagar Candida medium (Becton Dickinson Microbiology Systems, Cockeysville, Md., USA) and detecting the carbohydrate assimilation profiles using API 20C AUX Candida identifications kits (bioMérieux Vitek Inc., Hazelwood, Mo., USA). The formation of rough colonies with hyphal fringes and chlamydospores by Candida species on simplified sunflower seed agar was also observed, as done previously [19].

\section{Antimycotic Drugs and Media}

The 0.2\% CG mouthwash (Corsodyl, GlaxoSmithKline, Brentford, UK) was dissolved in sterile phosphate-buffered saline (PBS) at $\mathrm{pH}$ 7.2. Thereafter, three different concentrations of the antiseptic $(0.00125,0.0025$ and $0.005 \%)$ were prepared as solutions immediately before each experiment, as described previously $[16,17]$.

Candidal Cell Suspension Preparation for the Adhesion to BEC Assay, DAS Assay and CSH Assay

For the preparation of the cell suspension, a previously described method was employed with slight modifications $[16,17]$. In brief, Candida cells preserved on Sabouraud's dextrose agar were inoculated onto fresh plates and incubated overnight at $37^{\circ} \mathrm{C}$ 
for $24 \mathrm{~h}$. The organisms were harvested and thereafter a cell suspension was prepared using sterile PBS at $520 \mathrm{~nm}$ to obtain an optical density of 1.5 . Thereafter, $0.5 \mathrm{ml}$ of this cell suspension was mixed with $2 \mathrm{ml}$ of sterile PBS alone (control) and $2 \mathrm{ml}$ of PBS/CG (test), thereby producing a cell suspension of $10^{6}$ cells $\mathrm{ml}^{-1}$ in each assay tube. The tubes were then incubated at $37^{\circ} \mathrm{C}$ for a period of $30 \mathrm{~min}$. Following this limited exposure, the drugs were removed by dilution using sterile PBS. For this purpose three cycles of dilution with sterile PBS followed by centrifugation of the whole solution for $10 \mathrm{~min}$ at 3,000 $\mathrm{g}$ was carried out. Afterwards, the supernatant was completely removed and the remaining pellets of cells were resuspended in $15 \mathrm{ml}$ of sterile PBS. This procedure of drug removal by dilution was carried out in previous studies and was shown to reduce the concentration of CG by as much as 10,000 fold, resulting in the eradication of any carryover effect of CG after its removal $[16,17,20,21]$. Viable counts of the control and the test groups were also obtained subsequent to drug removal by evaluating colony-forming unit counts.

\section{Adhesion to BEC Assay}

For the adhesion to BEC assay, a previously used method [20] was performed with slight modifications. Briefly, human BEC from 4 adults (laboratory personnel) were obtained using sterile cotton swabs by softly rubbing the inner side of the right and left sides of the buccal mucosa of the mouth. Thereafter, the BEC were disseminated in sterile PBS. The suspension of pooled BEC from the four volunteers was washed in PBS and any attached organisms were removed by centrifugation at $3,500 \mathrm{~g}$ for $10 \mathrm{~min}$. The BEC were resuspended in sterile PBS to obtain a concentration of $1 \times$ $10^{5}$ cells/ml by hemocytometer counting. To execute the adhesion procedure, $0.75 \mathrm{ml}$ of BEC and $0.75 \mathrm{ml}$ of Candida cell suspension following brief exposure to $C G$ were gently mixed within plastic tubes and incubated at $37^{\circ} \mathrm{C}$ for a period of $1 \mathrm{~h}$. The Candida/BEC suspension was diluted using $5 \mathrm{ml}$ of sterile PBS. The BEC were harvested onto polycarbonate filters and gently washed with sterile PBS to remove any Candida cells unattached to BEC. Each polycarbonate filter was subsequently placed on a glass slide and removed gently after $10 \mathrm{~s}$. The glass slide preparation was air dried, Gram stained and prepared for BEC counting. The quantification of the number of adherent Candida cells was done under light microscopy at a magnification of $\times 400$. Fifty sequential BEC were perceived for the purpose of counting. Candida cells adhered to $\mathrm{BEC}$ were expressed as the number of yeasts per $50 \mathrm{BEC}$. Candida attached to folded or overlapping and clumped BEC were not counted.

\section{Adhesion to DAS Assay}

The acrylic strips for the adhesion assay was prepared as described previously $[11,12]$. Transparent self-polymerizing acrylic powder ( $1.5 \mathrm{~g}$ polymethyl methacrylate powder) was spread on an aluminum foil-covered glass slide $(2.5 \times 7.5 \mathrm{~cm})$. One milliliter of monomer liquid (Dentsply Ltd., Weybridge, UK) was poured onto the surface of the slide and immediately a second, similar slide was placed on top of the polymerizing mixture and the slides were firmly secured at both ends with two binder clips. After bench curing for $30 \mathrm{~min}$, the glass slides were separated. The resultant acrylic strips were cut into $5 \times 5 \mathrm{~mm}$ squares, then immersed in distilled water for 1 week to leach excess monomer and washed in running water for $3 \mathrm{~h}$. The strips were then disinfected by dipping in $70 \%$ alcohol and washed with sterile distilled water.
Next they were ultrasonicated for 20 min to remove any contaminants and artifacts from the surfaces, washed again in sterile distilled water, dried and used for the adhesion assay. The ensuing adhesion assay was executed as described previously $[11,12]$. In brief, using aseptic techniques, the acrylic strips were placed vertically in the wells of a sterile serological plate. Thereafter, following brief exposure to CG, $400 \mu$ l of Candida cell suspension was added to each well, completely covering the acrylic strips. The whole assembly was thereafter placed in an incubator for $1 \mathrm{~h}$ at $37^{\circ} \mathrm{C}$ with gentle agitation at $120 \mathrm{rpm}$. The strips were then recovered aseptically from the wells and washed three times by dipping gently in sterile PBS, which helped to dislodge the loosely attached Candida cells. The strips were then dried and stained using modified Gram stain without the counterstain. After air drying at room temperature they were mounted on glass slides with glycerol and the adherent Candida were quantified. Adherent Candida cells in 20 fields of view for each strip $\left(0.25 \mathrm{~mm}^{2}\right.$ per field $)$ were determined using a light microscope at $\times 400$ magnification, and the results were expressed as Candida cells $/ \mathrm{mm}^{2}$, as performed previously [21]. The majority of the attached Candida cells were in the blastospore stage (cells with a rounded format), some with daughter cells and only very few with hyphae or pseudohyphae. The following previously used parameters were used to standardize the counts: a budding yeast was considered to be a unit cell if the daughter was smaller than the mother cell, and a hypha was counted as a single cell [21].

\section{Relative CSH Assay}

For the assessment CSH on oral Candida species an aqueoushydrocarbon assay based on the biphasic separation of solutions was used as previously described [16, 17]. In brief, $5 \mathrm{ml}$ of Candida cell suspension following exposure to CG was mixed in a vortex. Thereafter, its absorbance was measured at $520 \mathrm{~nm}$. Subsequently, $1 \mathrm{ml}$ of xylene was added to the cell suspension. The test tubes were placed in an incubator at $37^{\circ} \mathrm{C}$ for $10 \mathrm{~min}$ to equilibrate. Thereafter, it was mixed in a vortex for $30 \mathrm{~s}$ and placed again in the incubator for a further $30 \mathrm{~min}$ to allow the aqueous phases and xylene to separate. The bottom aqueous phase of the sample was meticulously taken out with a pipette and placed in a sterile test tube. By bubbling air through the aqueous suspension at a rate of $180 \mathrm{ml}$ per minute for $2 \mathrm{~min}$, traces of contaminating xylene that may have been carried over in the pipette or bound to Candida cells was removed. The optical density (absorbance) was measured at $520 \mathrm{~nm}$ after mixing in a vortex for $5 \mathrm{~s}$ to disrupt and resuspend any aggregates that might have formed. The relative $\mathrm{CSH}$ was expressed as the reduction in the percentage of the optical density of the suspension, as done in previous studies [16, 17]. All tests were performed in duplicate on three separate occasions.

\section{Statistical Analysis}

The data obtained from the three different concentrations of CG on adhesion to BEC, DAS and CSH assays were analyzed using ANOVA Dunnett's t tests, with one group treated as a control (that unexposed to CG) against which all the other groups (exposed to CG) were compared. In addition, the mean percentage reduction of the two concentrations (i.e. 0.005 and $0.0025 \%$ ) of the Candida isolates tested, which had an overall significant effect in suppressing adhesion to BEC, DAS and CSH, was analyzed between C. albicans and the non-albicans species of Candida. 
Table 1. Adhesion of different oral Candida species to BEC (Candida/50 BEC) following brief exposure to three concentrations of CG

\begin{tabular}{|c|c|c|c|c|}
\hline Oral Candida species & Control & $0.00125 \%$ & $0.0025 \%$ & $0.005 \%$ \\
\hline \multicolumn{5}{|l|}{ C. albicans $(\mathrm{n}=10)$} \\
\hline Mean & 237.3 & 201.6 & 129.3 & 98.7 \\
\hline SEM & 4.10 & 3.71 & 2.52 & 4.22 \\
\hline Mean percentage reduction & & 15.04 & 45.51 & 58.41 \\
\hline $\mathrm{p}$ value & & 0.004 & $<0.001$ & $<0.001$ \\
\hline \multicolumn{5}{|l|}{ C. $k r u s e i ~(n=10)$} \\
\hline Mean & 120.4 & 99.1 & 55.8 & 37.8 \\
\hline SEM & 4.27 & 4.50 & 2.75 & 2.44 \\
\hline Mean percentage reduction & & 17.69 & 53.65 & 68.60 \\
\hline $\mathrm{p}$ value & & 0.003 & $<0.001$ & $<0.001$ \\
\hline \multicolumn{5}{|l|}{ C. tropicalis $(\mathrm{n}=10)$} \\
\hline Mean & 191.2 & 159.2 & 95.4 & 65.9 \\
\hline SEM & 6.18 & 2.90 & 3.46 & 5.69 \\
\hline Mean percentage reduction & & 16.74 & 50.10 & 65.53 \\
\hline $\mathrm{p}$ value & & $<0.001$ & $<0.001$ & $<0.001$ \\
\hline \multicolumn{5}{|l|}{ C. glabrata $(\mathrm{n}=10)$} \\
\hline Mean & 138.8 & 118.7 & 61.7 & 45.8 \\
\hline SEM & 2.47 & 3.52 & 3.08 & 3.54 \\
\hline Mean percentage reduction & & 14.48 & 55.55 & 67.00 \\
\hline $\mathrm{p}$ value & & $<0.001$ & $<0.001$ & $<0.001$ \\
\hline \multicolumn{5}{|l|}{ C. dubliniensis $(\mathrm{n}=10)$} \\
\hline Mean & 209.3 & 181.4 & 98.3 & 68.6 \\
\hline SEM & 5.44 & 5.54 & 2.04 & 1.94 \\
\hline Mean percentage reduction & & 13.33 & 53.03 & 67.22 \\
\hline $\mathrm{p}$ value & & 0.002 & $<0.001$ & $<0.001$ \\
\hline \multicolumn{5}{|l|}{ Candida species } \\
\hline Mean & 179.4 & 152.00 & 88.10 & 63.36 \\
\hline SEM & 21.81 & 19.08 & 13.41 & 10.59 \\
\hline Mean percentage reduction & & 15.27 & 50.89 & 64.68 \\
\hline $\mathrm{p}$ value & & 0.004 & $<0.001$ & $<0.001$ \\
\hline
\end{tabular}

\section{Results}

The mean adhesion to BEC of the 50 Candida isolates unexposed to CG was $179.4 \pm 21.81$ (yeasts/50 BEC), whereas following limited exposure to $0.00125,0.0025$ and $0.005 \%$ concentrations of CG there was a lessening in the adhesion to $152,88.10$ and 63.36 , respectively (table 1). Hence, compared to the controls, a marked diminution in the adhesion to BEC of all the isolates was seen following exposure to $0.005 \%$ CG, with a percentage reduction of $64.68 \%(\mathrm{p}<0.001)$. The suppressive effect on the adhesion to BEC following exposure to the $0.0025 \%$ dilution of the antiseptic was also significant $(\mathrm{p}<0.001)$, although lower than for the higher concentration $(50.89 \%$; table 1). Overall, although there was a significant reduction in the adhesion to BEC by the yeasts exposed to $0.00125 \%$ CG, this effect was only $15.27 \%$.
The mean adhesion to DAS of the 50 Candida isolates unexposed to CG was $46.80 \pm 0.39$ (yeasts $/ \mathrm{mm}^{2}$ ), whereas following brief exposure to $0.00125,0.0025$ and $0.005 \%$ concentrations of CG there was a decline in the adhesion to $43.34,27.71$ and 21.25 , respectively (table 2). Therefore, compared to the controls, a distinct reduction of $54.59 \%$ in adhesion to BEC of all the isolates was seen following exposure to $0.005 \%$ CG $(\mathrm{p}<0.001)$. Likewise, the suppressive impact on the adhesion to DAS following exposure to the $0.0025 \%$ dilution of the antiseptic was also significant $(\mathrm{p}<0.001)$, although lower than for the higher concentration (40.79\%; table 2). Even though there was a significant $7.39 \%$ reduction in adhesion to DAS of the yeasts exposed to $0.00125 \%$ CG, it was not very prominent compared to the higher concentrations.

The mean CSH of the Candida isolates unexposed CG was $27.67 \pm 4.06$, whereas following limited exposure to 
Table 2. Adhesion of different oral Candida species to DAS (cells $/ \mathrm{mm}^{2}$ ) following brief exposure to three concentrations of CG

\begin{tabular}{|c|c|c|c|c|}
\hline Oral Candida species & Control & $0.00125 \%$ & $0.0025 \%$ & $0.005 \%$ \\
\hline \multicolumn{5}{|l|}{ C. albicans $(\mathrm{n}=10)$} \\
\hline Mean & 46.03 & 43.07 & 32.36 & 26.89 \\
\hline SEM & 0.71 & 0.4 & 0.33 & 0.41 \\
\hline Mean percentage reduction & & 6.43 & 29.7 & 41.6 \\
\hline $\mathrm{p}$ value & & 0.003 & $<0.001$ & $<0.001$ \\
\hline \multicolumn{5}{|l|}{ C. krusei $(\mathrm{n}=10)$} \\
\hline Mean & 47.21 & 43.6 & 26.83 & 19.43 \\
\hline SEM & 0.61 & 0.38 & 0.41 & 0.4 \\
\hline Mean percentage reduction & & 7.65 & 43.17 & 58.84 \\
\hline $\mathrm{p}$ value & & $<0.001$ & $<0.001$ & $<0.001$ \\
\hline \multicolumn{5}{|l|}{ C. tropicalis $(\mathrm{n}=10)$} \\
\hline Mean & 46.1 & 43.22 & 25.9 & 19.63 \\
\hline SEM & 0.48 & 0.43 & 0.7 & 0.57 \\
\hline Mean percentage reduction & & 6.25 & 43.82 & 57.42 \\
\hline $\mathrm{p}$ value & & $<0.001$ & $<0.001$ & $<0.001$ \\
\hline \multicolumn{5}{|l|}{ C. glabrata $(\mathrm{n}=10)$} \\
\hline Mean & 46.65 & 43.75 & 27.36 & 19.74 \\
\hline SEM & 0.57 & 0.29 & 0.38 & 0.46 \\
\hline Mean percentage reduction & & 6.21 & 41.35 & 57.68 \\
\hline $\mathrm{p}$ value & & 0.001 & $<0.001$ & $<0.001$ \\
\hline \multicolumn{5}{|l|}{ C. dubliniensis $(\mathrm{n}=10)$} \\
\hline Mean & 46.58 & 43.06 & 26.12 & 20.55 \\
\hline SEM & 0.59 & 0.44 & 0.47 & 0.52 \\
\hline Mean percentage reduction & & 7.56 & 43.92 & 55.88 \\
\hline $\mathrm{p}$ value & & $<0.001$ & $<0.001$ & $<0.001$ \\
\hline \multicolumn{5}{|l|}{ Candida species } \\
\hline Mean & 46.80 & 43.34 & 27.71 & 21.25 \\
\hline SEM & 0.39 & 0.14 & 1.19 & 1.42 \\
\hline Mean percentage reduction & & 7.39 & 40.79 & 54.59 \\
\hline p value & & $<0.001$ & $<0.001$ & $<0.001$ \\
\hline
\end{tabular}

$0.00125,0.0025$ and $0.005 \%$ concentrations of CG there was a reduction in the CSH values to 26.51, 20.83 and 13.81 , respectively (table 3 ). Hence, compared to the controls, a striking reduction of $\mathrm{CSH}$ of all the isolates was seen following exposure to $0.005 \%$ CG, with a percentage reduction of $50 \%(\mathrm{p}<0.001)$. The suppressive effect on the $\mathrm{CSH}$ following exposure to the $0.0025 \%$ dilution of the antiseptic was also significant $(\mathrm{p}<0.001)$ in comparison with that of the unexposed control, although substantially lower than for the higher concentration (24.58\%; table 3). Although there was a very slight reduction in the $\mathrm{CSH}$ of all the yeasts exposed to $0.00125 \%$ CG (4.02\%; table 3), the suppressive outcome was not significant.

When the percentage reduction of the two concentrations (i.e. 0.005 and $0.0025 \%$ ) which had a significant effect in subduing adhesion attributes of all the Candida isolates was considered, it was noted that the suppressive effect on C. albicans isolates was the least compared to the non-albicans counterparts (tables 1-3). For instance, the reduction on adhesion to BEC of C. albicans isolates was $58.41 \%$ compared to $65.53-68.60 \%$ for the non-albicans species of Candida following exposure to $0.005 \%$ CG. Likewise, the reduction in DAS adhesion of C. albicans isolates was $41.6 \%$ compared to $55.88-58.84 \%$ for the non-albicans species of Candida following exposure to $0.005 \%$ CG. Similarly, the reduction in CSH of C. albicans isolates was $41.47 \%$ compared to $50.54-53.57 \%$ for the non-albicans species of Candida with this concentration. This difference was significant between C. albicans and non-albicans species of Candida ( $\mathrm{p}<0.05$ to $\mathrm{p}<0.001$ ). The reduction in adhesion to BEC by C. albicans isolates was $45.51 \%$ compared to $50.10-55.55 \%$ for the non-albicans species of Candida following exposure to $0.0025 \%$ CG. Likewise, the diminution of $C$. albicans isolates on 
Table 3. Relative CSH of different oral Candida species following brief exposure to three concentrations of CG

\begin{tabular}{|c|c|c|c|c|}
\hline Oral Candida species & Control & $0.00125 \%$ & $0.0025 \%$ & $0.005 \%$ \\
\hline \multicolumn{5}{|l|}{ C. albicans $(\mathrm{n}=10)$} \\
\hline Mean & 22.28 & 21.68 & 17.91 & 13.04 \\
\hline SEM & 0.28 & 0.31 & 0.26 & 0.43 \\
\hline Mean percentage reduction & & 2.69 & 19.61 & 41.47 \\
\hline $\mathrm{p}$ value & & 0.167 & $<0.001$ & $<0.001$ \\
\hline \multicolumn{5}{|l|}{ C. krusei $(\mathrm{n}=10)$} \\
\hline Mean & 30.24 & 28.80 & 22.53 & 14.92 \\
\hline SEM & 0.51 & 0.28 & 0.35 & 0.31 \\
\hline Mean percentage reduction & & 4.76 & 25.50 & 50.66 \\
\hline $\mathrm{p}$ value & & 0.025 & $<0.001$ & $<0.001$ \\
\hline \multicolumn{5}{|l|}{ C. tropicalis $(\mathrm{n}=10)$} \\
\hline Mean & 37.79 & 36.39 & 27.91 & 18.69 \\
\hline SEM & 0.54 & 0.35 & 0.51 & 1.19 \\
\hline Mean percentage reduction & & 3.70 & 26.14 & 50.54 \\
\hline $\mathrm{p}$ value & & 0.042 & $<0.001$ & $<0.001$ \\
\hline \multicolumn{5}{|l|}{ C. glabrata $(\mathrm{n}=10)$} \\
\hline Mean & 32.95 & 31.72 & 25.16 & 15.30 \\
\hline SEM & 0.67 & 0.41 & 0.68 & 1.05 \\
\hline Mean percentage reduction & & 3.73 & 23.64 & 53.57 \\
\hline p value & & 0.134 & $<0.001$ & $<0.001$ \\
\hline \multicolumn{5}{|l|}{ C. dubliniensis $(\mathrm{n}=10)$} \\
\hline Mean for Candida species & 14.86 & 13.95 & 10.66 & 7.09 \\
\hline SEM & 0.93 & 0.87 & 0.52 & 0.36 \\
\hline Mean percentage reduction & & 6.12 & 28.26 & 52.29 \\
\hline p value & & 0.484 & $<0.001$ & $<0.001$ \\
\hline \multicolumn{5}{|l|}{ Candida species } \\
\hline Mean & 27.62 & 26.51 & 20.83 & 13.81 \\
\hline SEM & 4.06 & 3.94 & 3.03 & 1.91 \\
\hline Mean percentage reduction & & 4.02 & 24.58 & 50.00 \\
\hline p value & & 0.537 & $<0.001$ & $<0.001$ \\
\hline
\end{tabular}

adhesion to DAS was $29.7 \%$ compared to $41.35-43.92 \%$ for the non-albicans species of Candida following exposure to $0.0025 \%$ CG. Similarly, the reduction in CSH of C. albicans isolates was $19.61 \%$ compared to $23.64-$ $28.26 \%$ for the non-albicans species of Candida with this concentration. This difference was also significant between $C$. albicans and non-albicans species of Candida $(\mathrm{p}<0.001)$.

\section{Discussion}

In this study brief exposure to subtherapeutic concentrations of CG suppressed the candidal adherence to BEC and DAS of all the Candida species tested. The discerned overall significant suppression of Candida adhesion to $\mathrm{BEC}$ and DAS due to CG is related to the pharmacodynamic interactions between the antiseptic and the Can- dida cell wall. Scanning and transmission electron micrographic observations showed that the antifungal effect of CG was most likely due to a loss of cytoplasmic components along with the coagulation of nucleoproteins and associated morphological changes in the cell wall structure [23]. Furthermore, a decreased budding or germinating of Candida cells was also observed [23]. Interestingly, other chlorhexidine derivatives, such as chlorhexidine diacetate, have also generated cytological changes in yeast species such as Saccharomyces cerevisiae, involving dense and granular cytoplasmic constituents, withdrawal of the interior constituents from the cell wall and a general loss of the typical cellular organization [24]. Moreover, chlorhexidine-induced leakage of $\mathrm{K}^{+}$and pentose material from S. cerevisiae and protoplast lysis has also been documented [25]. Considering these probable effects of CG and other chlorhexidine derivatives on yeast species, it is reasonable to speculate that, by affecting both the cell 
wall structure as well as other cellular events, CG could explain the suppression of the adhesion of Candida to BEC as well as DAS.

Microbial structures that contribute to the $\mathrm{CSH}$ include outer membrane proteins, lipoproteins, phospholipids, lipopolysaccharides and fimbriae [26, 27]. Hence, drugs that perturb these structural features have been shown to reduce the $\mathrm{CSH}$ of microbes $[16,17]$. In the case of $C$. albicans, it has been shown that $\mathrm{CSH}$ correlates well with the concentration of 'fibrils' in the exterior layer of the cell wall $[26,27]$. In addition, the antifungal effect of this antiseptic is most likely a result of a loss of cytoplasmic components and coagulation of nucleo-proteins and associated morphological changes in the cell wall structure of Candida [23]. Therefore, it is tempting to speculate that even low, subtherapeutic concentrations of CG may affect the cell wall structure to some extent, and suppress the CSH of Candida species.

When the relative interspecies variation of the impact of CG was compared, it was evident that the antiseptic had the least impact on the adhesion to BEC, DAS and relative $\mathrm{CSH}$ of $C$. albicans when exposed to two concentrations (i.e. 0.005 and $0.0025 \%$ ) of CG. Hence, it appears that of all the Candida species studied, C. albicans to be the most resilient compared to the non-albicans species of Candida. This observation adds further credence to the fact that C. albicans is the most virulent and pervasive of all the Candida species [28].

The current study revealed that the exposure of oral Candida species to CG even at subtherapeutic levels suppressed three major virulent attributes of the yeast that dictates its mucosal colonization. Of importance to the geographical locale, a recent report indicates that $C . d u b$ liniensis was the most prevalent of the non-albicans oral Candida species isolated from Kuwait [19]. There are also reports of the emergence of resistance to 5-fluorocytosine, a potent DNA-analogue antifungal, in Candida isolates from Kuwait and contiguous locales of the Middle East $[29,30]$. In addition, resistance to nearly all antifungal agents has been reported in virtually all clinical Candida species [2-7, 28-30]. The emergence of such resistance has important therapeutic implications and indicate the need for possible alternative antifungal strategies. In this context our results seem to add further credence to the use of CG in vivo as an adjunct in the management of oral candidosis.

\section{Conclusion}

In this study CG induced a suppression of the adhesion to BEC, DAS and CSH in five different Candida species obtained from a single geographic location in the Middle East.

\section{Acknowledgments}

This work was supported by Kuwait University Research Grant No. DB 01/13 and partially supported by Kuwait University General Facility Project Grant No. GD 01/11. Technical support and advice are gratefully acknowledged from Dr. J.A.M.S. Jayathilake, Faculty of Dental Sciences, University of Peradeniya, Sri Lanka, Dr. Bobby Joseph, Ms. Preethi John and Ms. Lovely James, Faculty of Dentistry, Kuwait University, Kuwait. The contribution of Dr. P. Sharma to the statistical analysis of data is much appreciated.

\section{References}

1 McCullough M, Patton LL, Coogan M, et al: New approaches to Candida and oral mycotic infections: workshop 2A. Adv Dent Res 2011; 23:152-158.

2 Samaranayake YH, Samaranayake LP: Candida krusei: biology, epidemiology, pathogenicity and clinical manifestations of an emerging pathogen. J Med Microbiol 1994;41:295-310.

- 3 Pfaller MA, Diekema DJ: Epidemiology of invasive candidiasis: a persistent public health problem. Clin Microbiol Rev 2007;20:133-163.

-4 Moran GP, Sullivan DJ, Henman MC, et al: Antifungal drug susceptibilities of oral Candida dubliniensis isolates from human immunodeficiency virus (HIV)-infected and non-infected subjects and generation of stable fluconazoleresistant derivatives in vitro. Antimicrob Agents Chemother 1997;41:617-623.
5 Fanci R: Breakthrough Candida dubliniensis fungemia in an acute myeloid leukemia patient during voriconazole therapy successfully treated with caspofungin. J Chemother 2009;21:105-107.

6 Fleischhacker M, Pasligh J, Moran G, et al: Longitudinal genotyping of Candida dubliniensis isolates reveals strain maintenance, microevolution, and the emergence of itraconazole resistance. J Clin Microbiol 2010;48: 1643-1650.

7 Huang M, Kao KC: Population dynamics and the evolution of antifungal drug resistance in Candida albicans. FEMS Microbiol Lett 2012; 333:85-93.

-8 Samaranayake YH, Samaranayake LP: Experimental oral candidiasis in animal models. Clin Microbiol Rev 2001;14:398-429.
9 Klotz SA, Drutz DJ, Zajic JE: Factors governing adherence of Candida species to plastic surfaces. Infect Immun 1985;50:97-101.

$\checkmark 10$ Hazen KC, Hazen BW: Surface hydrophobic and hydrophilic protein alterations in Candida albicans. FEMS Microbiol Lett 1993;107: 83-87.

11 Panagoda GJ, Samaranayake LP: The relationship between the cell length, adhesion to acrylic and relative cell surface hydrophobicity of Candida parapsilosis. Med Mycol 1998; 36:373-378.

12 Panagoda GJ, Ellepola AN, Samaranayake LP: Adhesion to denture acrylic surfaces and relative cell-surface hydrophobicity of Candida parapsilosis and Candida albicans. APMIS 1998;106:736-742. 
13 MacNeill S, Rindler E, Walker A, et al: Effects of tetracycline hydrochloride and chlorhexidine gluconate on Candida albicans: an in vitro study. J Clin Periodontol 1997;24:753760.

14 Budtz-Jorgensen E: Candida-associated denture stomatitis and angular chelitis; in Samaranayake LP, MacFarlane TW (eds): Oral Candidosis, ed 1. London, Wright Butterworth, 1990, pp 156-183.

15 Darwazeh AM, Lamey PJ, MacFarlane TW, et al: The effect of exposure to chlorhexidine gluconate in vitro and in vivo on in vitro adhesion of Candida albicans to buccal epithelial cells from diabetic and non-diabetic subjects. J Oral Pathol Med 1994;23:130-132.

16 Ellepola AN, Joseph BK, Khan ZU: Cell surface hydrophobicity of oral Candida dubliniensis isolates following limited exposure to sub-therapeutic concentrations of chlorhexidine gluconate. Mycoses 2013;56:82-88.

17 Ellepola AN, Joseph BK, Khan ZU: Changes in cell surface hydrophobicity of oral Candida albicans from smokers, diabetics, asthmatics and healthy individuals following limited exposure to chlorhexidine gluconate. Med Princ Pract 2013;22:250-254.

18 Bonesvoll P, Lökken P, Rölla G, et al: Retention of chlorhexidine in the human oral cavity after mouth rinses. Arch Oral Biol 1974;19: 209-212.
19 Ellepola AN, Khan ZU, Joseph BJ, et al: Prevalence of Candida dubliniensis among oral Candida isolates in patients attending the Kuwait University Dental Clinic. Med Princ Pract 2011;20:271-276.

20 Ellepola AN, Chandy R, Khan ZU: Post-antifungal effect and adhesion to buccal epithelial cells of oral Candida dubliniensis isolates subsequent to limited exposure to amphotericin $\mathrm{B}$, ketoconazole and fluconazole. J Investig Clin Dent 2015;6:186-192.

21 Ellepola AN, Joseph BK, Altarakemah Y, et al: In vitro adhesion of oral Candida dubliniensis isolates to acrylic denture surfaces following brief exposure to sub-cidal concentrations of polyenes, azoles and chlorhexidine. Med Princ Pract 2015;24:58-64.

22 Ellepola AN, Samaranayake LP: Adjunctive use of chlorhexidine in oral candidoses: a review. Oral Dis 2001;7:11-17.

23 Bobichon H, Bouchet P: Action of chlorhexidine on budding Candida albicans: scanning and transmission electron microscopic study. Mycopathologia 1987;100:27-35.

24 Hiom SJ, Furr JR, Russell AD, et al: The possible role of yeast cell walls in modifying cellular response to chlorhexidine diacetate. $\mathrm{Cy}$ tobios 1996;86:123-135.
25 Hiom SJ, Furr JR, Russell AD: Effects of chlorhexidine diacetate and cetylpyridinium chloride on whole cells and protoplasts of Saccharomyces cerevisiae. Microbios 1993;74: 111-120.

26 Shibl AM, Ramadan MA, Tawfik AK: Postantibiotic effect of roxithromycin on streptolysin $\mathrm{O}$ production, hydrophobicity, and bactericidal activity of PMNL by Streptococcus pyogenes. Diagn Microbiol Infect Dis 1994;20: 7-11.

27 Hazen KC, Hazen BW: Hydrophobic surface protein masking by the opportunistic fungal pathogen Candida albicans. Infect Immun 1992;60:1499-1508.

28 Ellepola AN, Samaranayake LP: Oral candidal infections and antimycotics. Crit Rev Oral Biol Med 2000;11:172-198.

29 Ahmad S, Khan ZU, Joseph L, et al: Genotypic heterogeneity and molecular basis of 5-flucytosine resistance among Candida dubliniensis isolates recovered from clinical specimens in Kuwait. Med Mycol 2012;50: 244-251.

30 Al Mosaid A, Sullivan DJ, Polacheck I, et al: Noval 5-flucytosine clade of Candida dubliniensis from Saudi Arabia and Egypt by CD25 fingerprinting. J Clinic Microbiol 2005;43: 4026-4036. 